\title{
Chapter 23 \\ Older People in Long-Term Care Institutions: A Case of Multidimensional Social Exclusion
}

\author{
Feliciano Villar, Rodrigo Serrat, Annette Bilfeldt, and Joe Larragy
}

\subsection{Introduction}

Residential care (or care homes) are communal living settings with various levels of health and psychosocial support aimed at improving the quality of life of residents. They include a range of different services provided by public, private (for-profit and not-for-profit), social- or health-care agencies and professionals. For the sake of simplicity, in this chapter we use the term "care homes" referring to a range of such facilities, differentiating among them where necessary.

If we define social exclusion broadly as the separation of individuals and groups from mainstream society (Moffatt and Glasgow 2009) it is evident that living in a care home involves challenges connected to a lack of opportunities to participate in key activities inside and outside of the institution. In this sense, care homes (and particularly those that follow what is described as a "traditional care culture") might be one of the remaining examples of what Goffman (1961) calls "total institutions", in which people are isolated from the wider community and lead an enclosed and regulated life formally monitored and controlled by professionals.

Such risks of exclusion might be exacerbated by the profile of the older population living in care homes. Older people living in care homes typically have multiple health and social care needs, with the prevalence of depression and dementia being particularly high. For example, up to $70 \%$ of care home residents in countries such as England (Alzheimer's Society 2016) or Norway (Selbaek et al. 2007) have been

\footnotetext{
F. Villar $(\bowtie) \cdot$ R. Serrat

Department of Cognition, Development and Educational Psychology,

University of Barcelona, Barcelona, Spain

e-mail: fvillar@ub.edu
}

\author{
A. Bilfeldt \\ University of Greenland, Nuuk, Greenland \\ J. Larragy \\ Maynooth University, Kildare, Ireland
}


reported to have dementia. The presence of dependency and particularly of mental and physical health conditions increases the risk of social exclusion and the potential for violation of basic rights of people living in care homes (Cahill 2018).

Although in developed countries the quality of care offered by institutions has improved dramatically in recent decades, according to Alzheimer Disease International (2013) standards of care for those living in residential care are still far from perfect. It is on this basis that this chapter aims to explore the risks of social exclusion posed for older people living in a care home in relation to enjoy meaningful social relationships, to actively contribute to the institution and also to the wider community, and to exert control over their own life.

In focusing on these facets, the chapter will consider two domains of exclusion. We begin with exclusion from social relationships, and then follow by considering civic engagement and socio-cultural aspects, as components of the broad domain of civic exclusion [please see Walsh et al. this volume for a discussion]. We end the chapter by raising some brief conclusions concerning these areas, and their interrelationship, to advance work on this topic.

\subsection{Exclusion from Social Relationships}

Connecting with other people and having emotionally significant human relationships is a basic human need that must be maintained for older people living in care homes. Thus, social relationships have been repeatedly identified as essential to nursing home residents' quality of life (Roberts and Bowers 2015). Residents who do not have relevant social networks and are not socially engaged are at higher risk of depression and other negative health outcomes (Drageset 2004).

One might expect that care homes, being a communal living setting, could be a good place to enjoy varied and significant social relationships. After all, older people living in care homes are surrounded by other residents and by staff most of the day and, in fact, finding spaces to be alone and maintaining aspects of personal privacy has been repeatedly reported as one of the major problems older people living in institutions have to face (Pitkala 2016). Unfortunately, simply being in the same space and time with other people is not enough to address the emotional and existential dimensions of social relationships: on the contrary, the evidence suggests that loneliness is a prevalent phenomenon for people living in long-term care homes, where opportunities to meet the need for intimacy, closeness and touch are seriously restricted. For instance, in a study with older people without cognitive impairments living in nursing homes, Drageset et al. (2011) found that more than half experienced loneliness, and this is similar to the levels found in other studies exploring self-perceived loneliness among older people living in institutions (e.g. Nyqvist et al. 2013).

To understand why loneliness is so prevalent among older people living in care homes, several factors should be taken into account. Firstly, some studies have found that older people who have either lost significant social relations (e.g. through 
bereavement - see Urbaniak et al. this volume), or are experiencing loneliness in the community, are more likely to move into a care home (Hanratty et al. 2018). Secondly, many of the characteristics of care home users, such as being female, with low income, with disabilities and health conditions, or with cognitive impairments, are also risk factors for loneliness [see Morgan et al. this volume]. In addition, the transition to living in a care home might in itself cut off pre-existing social relations and reduce possibilities for replacing these relationships and establishing new bonds. For many residents, moving into a care home is a stressful event involving the loss of relatives and friends, and a diminished lifestyle, and might lead to a grief that makes it even more difficult to establish new significant relationships (Löfqvist et al. 2013). Moreover, residents might have problems making meaningful social connections without explicit support (Cipriani et al. 2006), a difficulty that is even greater if they experience mobility restrictions or, as in the case of dementia, communication impairments (Alzheimer Disease International 2013).

Apart from the lack of relationships with other care home users, studies focused on social relationships of older people living in institutional settings have emphasised the deficiency of communication and bonds with supporting staff. For instance, tight time schedules, frequent among staff working in care homes, might lead to a daily practice without dialogue and meaningful social contact between the resident and the employee, whereupon important knowledge about the resident's social and emotional needs is lacking (Andersen and Bilfeldt 2016). One study found that, aside from time spent receiving care, residents spent only two minutes within a six hour period interacting with other residents or staff (Alzheimer's Society 2007). This communicational isolation seems to be particularly severe for people with dementia [also see Andersen et al. this volume]. Using video recordings of daily life conversations in long-term care institutions for older people, Ward et al. (2008) estimated that people with dementia living in a care home spent just $10 \%$ of their awake time interacting with other people, with $75 \%$ of this time corresponding to interactions with visitors (mainly close relatives) and the remaining $25 \%$ corresponding to interactions with staff or other residents. In many care homes, interests of the staff seem to overshadow the wishes of the residents; and professionals rarely establish any communication with people with dementia beyond their assigned tasks, preferring to interact among themselves, even when the person with dementia was physically present (Doyle and Rubinstein 2013).

Labelling and depersonalising older people living in care homes (and particularly people with dementia) not only discourages communication and contributes to neglect, but also lowers the quality of the few interactions that they do have. Williams et al. (2016) highlight that in institutional settings contact between residents and staff tends to focus on instrumental care-related activities, trying to get the resident to cooperate in daily tasks, including activities of daily living, bodily functions, or health assessments. Consequently, talk is often initiated and directed by the caregiver and is often instructional, consisting of a set of short standardised imperative sentences and evaluative comments about the task being performed, with few opportunities for the resident to participate actively in the exchange (Allan and Killick 2014). This way of communicating exemplifies how staff prioritise getting 
through their work over addressing any of the emotional and social needs of the person that could be met by the interaction. Where residents are treated as frail bodies and objects it is overlooked that they are persons who are capable of expressing needs and possess a unique perspective on the world (Westerhof et al. 2013).

The consequence is a kind of extreme social exclusion and unequal interactions that disempower and disenable older people living in care homes, leading residents to experience lack of influence and autonomy (Bilfeldt et al. 2018) and confirming stereotypes of "persons-in-need". Older people may experience loneliness when they are increasingly limited in body with increased dependency on others (Paque et al. 2018). In the worst case, depersonalisation might lead to neglect or abuse whose consequences go far beyond relational or emotional outcomes (Phelan 2015).

Social and communicational neglect within these institutions is usually not intentional. Rather, it can happen due to the very nature of the institutional setting, the task-orientation of staff and the focus on efficiency. In this sense, the tendency towards "batch" treatment of residents is compelling and expedient from the perspective of the institution. This tendency is strong and reinforced by the context and day to day routine even of "well-run" care settings. Establishing a relationship between the resident and one or a few committed care personnel may be essential for feeling emotional closeness (Drageset et al. 2011) and requires that management staff and primary nurses should emphasise the psychosocial needs of the residents. Awareness of these constraints has been suggested as key to making a cultural shift within the care setting to enable and encourage opportunities for personal friendships and new emotional bonds to emerge.

Even where residents are provided with a variety of social programmes, these are again mostly planned and implemented using a "task-oriented" rigidly scheduled approach (Wiersma and Dupuis 2010), without input from residents. When residential care involves being catered to and entertained - like a continuous vacation - the routine may remove even minor challenges and stifle opportunities important for taking initiative, forming meaningful connections and achieving personal growth. A task-oriented approach obscures what is really needed, which is a space where residents can speak and be heard. Indeed, despite the ideals and best efforts of staff, residents often complain of a lack of meaning (Choi et al. 2008) and limited chances for reciprocity or contribution (Van Malderen et al. 2013).

\subsection{Civic Engagement}

Opportunities for civic engagement are extremely limited for those living in a care home (Leedahl et al. 2017). Although research on older people's civic engagement has grown steadily in recent decades (Serrat et al. 2020), care home residents are largely overlooked because the focus has been mainly on healthy, communitydwelling older people. This is ironic given that civic engagement has been associated with a wide range of positive outcomes, from higher levels of cognitive function or mental and physical health to reduced feelings of loneliness (Serrat et al. 2020). 
Civic engagement, therefore, could be particularly relevant for older people living in care homes.

Civic engagement refers to ways in which " $\ldots$. an active citizen participates in the life of a community in order to improve conditions for others or to help shape the community's future" (Adler and Goggin 2005, p. 16). As a multidimensional concept, civic engagement entails both volunteering and political activities. Volunteering activities are aimed at improving conditions for others, with no explicit political intention, and could be carried out informally (referred to as informal volunteering; e.g. helping friends or relatives) or channelled through organizations (termed formal volunteering; e.g. participating in NGOs or community organizations). Political activity seeking to influence decision making processes, spans basic institutionalised activities directly related to government, $e$.g. voting or contacting representatives, and more advanced engagement outside the sphere of state politics in the form of non-institutionalised political activities, such as campaigning and participating in protest activities) (Serrat et al. 2020).

While volunteering activities may take place both inside and outside care homes, political activities are more likely to occur exclusively outside them. Indeed, when it comes to considering civic engagement among older people living in care homes, one should not overlook residents' councils as well as other similar mechanisms grouped under the label of client engagement (Petriwskyj et al. 2018). Enabling older people to voice grievances, and be heard in decision-making processes affecting their care environment, may even constitute important manifestations that can connect to wider political engagement.

The limited research on care home residents' engagement in civic activities has so far addressed three of these types of civic engagement: formal volunteering (e.g. Klinedinst and Resnick 2014), institutionalised political activities (particularly voting; e.g. Bonnie et al. 2018), and client engagement initiatives (e.g. O'Dwyer and Timonen 2010). In the following paragraphs we briefly review the main results of these streams of research.

Research on older residents' formal volunteering shows that they tend to participate less than community-dwelling older people, especially if they are among the oldest old or live with chronic health problems or disabilities (Resnick et al. 2013; Leedahl et al. 2017). Moreover, those who do engage civically are far more likely to do so inside rather than outside the care home (Resnick et al. 2013). The literature highlights a number of barriers for promoting greater engagement, from those which are related to residents' diminished personal resources (e.g. cognitive impairment), to practical issues (e.g. mobility, transportation) to contextual issues (e.g. staff attitudes towards residents' participation, ageism, and ableism) (Anderson and Dabelko-Schoeny 2010). Although the evidence on the effects of engagement in volunteering activities on residents' health and well-being is scarce and mixed, a small number of studies show positive impacts on life satisfaction (Yuen 2002) and feelings of usefulness (Klinedinst and Resnick 2014).

Moving to research on older residents' voting behaviour, this has been underpinned by ethical and legal discussions concerning the assessment and determination of voting competence among people with dementia (Appelbaum et al. 2005). 
This debate highlights the complex tension between avoiding fraud and manipulation of residents with decreased cognitive capacity and preserving as far as possible their right to freely participate in the electoral processes (Bonnie et al. 2018). Although many national and international organisations advocate for assuring the effective and full participation of persons with disabilities in political and public life, research has shown that people with dementia tend to be intentionally or inadvertently disenfranchised (Karlawish et al. 2008). However, as Appelbaum et al. (2005) have demonstrated, most people with low to moderate cognitive impairment are cognitively able to vote, so dementia diagnosis by itself should never be an argument for disenfranchisement. Moreover, just as in the case of formal volunteering, organizational and contextual factors are important barriers to older residents' voting participation. In their study addressing voting behaviour among residents of care homes in Virginia (US), for instance, Bonnie et al. (2018) show that organizational policy and practices facilitating registration and voting have a positive effect on voter turnout among residents.

Finally, client engagement refers to initiatives allowing older people "...to have a voice - and control - in the services they receive as well as the policy that guides these" (Petriwskyj et al. 2018, p. 1351). These initiatives vary, both in scope, from participating in decisions about one's care to being involved in the management of the facility, and in depth, from mere consultation and discussion to collaboration, co-production, and true empowerment of residents. Research on client engagement initiatives have highlighted the difficulties associated with their implementation, including narrowing it to a mere consumerist approach (O'Dwyer 2013), or reinforcing tokenism and lack of influence of residents (e.g. O'Dwyer and Timonen 2010).

\subsection{Socio-Cultural Exclusion}

One important aspect of civic exclusion and broader processes of social exclusion for older people living in care homes relates to culture of care, and specifically how it can work to ameliorate or intensify socio-cultural aspects of exclusion. Cultures of care (Cassie and Cassie 2012; Fine 2015) involve a set of shared values, beliefs, expectations and practices (i.e., a socio-cultural mindset) about what is supposed to be "good care" and which define both the responsibilities of staff and the position of older people ("users") in a care relationship. Thus, certain cultures of care could give rise, propagate and justify forms of exclusion, discriminatory practices and stigmatization of older people living in care homes. It is in that sense that we can talk about socio-cultural aspects of civic exclusion. These mechanisms can arise from or manifest within relationships with staff and others, and/or can drive experiences of exclusion across the social and civic lives of older people in residential facilities.

Traditionally, the culture of care in institutions for older people has been defined by task- or service-orientation whereby care is conceived as a service provided by professionals. Such professionals, coming from health and social fields, are within 
this system positioned as experts who have the necessary technical knowledge enabling them to determine what type of care is needed (that is to diagnose user needs and prescribe care) and how and to what degree it should be offered.

On this view, care involves a number of supporting tasks in some core areas, mainly related to basic activities of daily living (e.g. feeding, bathing and hygiene, mobility, etc.), security and avoidance of risks. In such cases, quality of care has to do with achieving certain outcomes, such as maximizing resident autonomy, reducing undesirable symptoms or states and increasing users' quality of life. This has led to the inclusion of psychosocial activities, both with recreational or therapeutic intention, among the tasks to be done in care homes. To assure quality, there is an emphasis on following protocols that define best practice processes, and on standardization of care, both of which contribute to care efficiency and the completion of care tasks with the least possible cost. That principle tends to involve a high degree of formalization, requiring employees to follow strict policies, schedules and procedures, and a rigid and markedly hierarchical division of responsibilities.

The New Public Management (NPM) quality control system allocates resources by the way of organizing principles aimed at cost reduction. The foundation of the allocation of resources in older adult care quality is becoming increasingly organised through principles that were originally developed for industrial production and whose main purpose has been the production of homogeneous services in a standardised way. Under these standards, the employee might end up in a paradoxical situation where care giving is conducted through homogeneous procedures instead of being conducted according to the individual needs of human beings. Increasingly, efficiency requirements and protocolization of services in detailed work descriptions lead to low priority being given to individual differences in needs and to the social dimensions of care (Szebehely 2005; Hjort 2009; Andersen and Bilfeldt 2016; Szebehely et al. 2017), with both excluded from the basis of work organization.

This technical and task-oriented culture of care often assumes that older people are merely passive care-receiving users. As Goffman (1961) would say, individuals' identities are stripped away, just to be thought of using standard (e.g. "patient", "resident") or diagnostic labels (e.g. "demented"). In other words, older persons are defined by their deficiencies, needs and vulnerabilities, which may be viewed as intrinsic and biomedical in nature with little susceptibility to change or improvement.

Such positioning of older people living in care homes as mere recipients of care accounts for some ageist practices contributing to social exclusion. One of the most studied examples of this is infantilisation, which is often manifest in the use of "elderspeak" by institutional staff (Williams et al. 2016). Elderspeak consists of speaking more slowly and using inappropriate terms of endearment, exaggerated intonation, simplified syntax, or questions that indicate a desired response (Brown and Draper 2003). However, as well-meaning as this may be, the use of elderspeak presupposes dependency and lack of competence, contributing to the construction of condescending and paternalistic relationships. Such a culture of care stigmatises older people and, in some cases, can lead to disruptive behaviors and resistance to care (Williams et al. 2017). 
These sort of practices can contribute to what some authors, such as Sabat (2006), have called "excess disability", i.e., dependency shaped by disabling cultural and environmental factors rather than physical or endogenous disease factors. Thus, defining older people as "dependent", with few or no opportunities for improvement, acts as a self-fulfilling prophecy and is linked to helplessness and learned dependency. In particular, where staff work under great pressure to perform certain care assignments in a short time, it may become expedient to presume a low level of functioning among residents and in turn restrict the opportunities to sustain and reinforce remaining competences (Stone and Bryant 2012). In some cases, older people may accommodate to such unsolicited support, and behave in a way that only confirms initial low expectations of functioning. In others, such dysfunctional interactions may elicit disruptive behaviors and expressions of discomfort that are interpreted as a symptom of disease, thereby reinforcing the initial presumption of a lack of competence (Scholl and Sabat 2008).

In any care relationship we find an imbalance of power between people living in care and those providing care (Roberts and Bowers 2015), which in turn could contribute to the marginalisation of older adult residents. Positioned as persons-in-need, older people living in institutions can develop very low expectations of their lives and about the support provided, causing them to lose autonomy and become dependent on others who determine their activities, and the rules governing daily life. Thus, the opportunities for people living in care homes to express themselves and let their voices be heard are dramatically diminished, even affecting older people's assessment of whether they are happy, and their ability to speak out if they are not.

\subsection{Discussion}

In this chapter we have explored the multidimensional and interrelated nature of exclusion in the context of institutional care settings for older people. First, we identified challenges in relation to fostering opportunities for continuity and evolution of the intimate, emotional and social facets of a person's life and relationships, which are either disrupted or intensified by admission to a residential care setting. A second dimension that typically gets lost in care settings, on admission, is continuity as a citizen of the care setting, and the opportunity for engagement (rather than merely an inmate, resident, consumer or user), both as a rights-bearer, and conceivably indeed as a duty-bearer. A third and probably broader dimension that underlies any form of exclusion in care homes has to do with the socio-cultural representations of care, whereby the individual may be dispossessed of a personal narrative by institutional and professional over-determining.

These three facets are related and reinforce each other to crystalise a social exclusion status that could be difficult to revert. For instance, a task-oriented culture of care that sees older people living in long-term care facilities exclusively through the lens of deficit may lead to relational and communicational patterns centered just on the completion of basic everyday activities, such as feeding or toileting, and 
forgetting socio-emotional needs that are not considered essential. In turn, such exclusion from social relationships hampers the capacity of controlling and deciding over their own life, and inhibits remaining capacities to reclaim and exert civic rights, promoting disempowerment. As a result, the initial views of older people as "people in need" and a task-oriented conception of care are reinforced.

However, there are ways to get out of these vicious circles. In recent decades we have witnessed increasing efforts to reverse such circumstances and substitute traditional biomedical and task-oriented protocols for a more holistic and individualised model of elder care, "person-centred care" (PCC). Rather than a single model, PCC is an approach with some core common assumptions considered as essential to provide quality care. Among them, most authors (e.g. Brooker 2004; Edvardsson et al. 2010; Doyle and Rubinstein 2013) mention: (1) the recognition of residents' personhood, exemplified in their life story, values and preferences, and their unique perspective of the world; and (2) the emphasis on empowerment of older people in the course of communication between caregivers and older people while performing daily care tasks, and on providing emotional (as distinct from instrumental or technical) support. The steady expansion of the PCC model in the latest decades, a model that has become the standard of good care at least in Western countries, is without a doubt a major breakthrough to reverse social exclusion in long-term care facilities.

While PCC models emphasise the concept of personhood to preserve the identity and reinforce the social bonds of older people living in long-term care facilities (and particularly, of those living with dementia), some authors have proposed to complement personhood with the concept of social citizenship, a more socially and politically oriented model that pays attention to issues of power, inclusion, and citizenship (e.g. Baldwin 2008; Bartlett and Connor 2010). The concept of social citizenship has a long pedigree since the publication of Marshall's seminal essay (Marshall 1950) in which he set out citizenship in more complete terms, encompassing civil rights, political rights and social rights. In the present context the concept is valuable in offering a paradigm that shifts the discourse around long-term care institutions by recognizing the challenge of realizing rights and citizenship in this rounded sense in the context of care homes for older people. It sets a norm, or goal, for which pathways to the realization of care tasks will need to be found, based on the notion that citizenship is the highest expression of human engagement. In the context of long- term care, the breach may be less of a problem in relation to meeting basic material dimensions of welfare, than in the areas of recognition of the older person's integrity, freedom, right to be self-governing and part of the "polity", whether defined in relation to the institutional context or the wider setting.

\subsection{Conclusion}

The exercise of rights as a citizen more generally, in the wider community and society, is critical to the individual. In fact, it is also key to the vindication of citizenship as the global principle of inclusion for a world where reaching deep old-age will 
become the norm. In sum, several domains of exclusion in later life, which may be accentuated in the residential care setting, could be addressed more effectively through the application of a coherent concept of citizenship.

\section{Authors' Postscript}

The outbreak in 2019 of the SARS CoV-2 (COVID-19) pandemic has had an unprecedented impact on long-term care institutions for older people in terms of the number of cases, the severity of these cases, and fatalities. Some of the decisions and measures discussed (or already taken) to cope with the pandemic in these institutions, such as the implementation of a particularly strict confinement and social distancing measures, the 'medicalisation' of these institutions that could make them more like hospitals and less like places to live, or the consideration of older people (and especially those living in care homes) as an at-risk group using a crude chronological criteria, might increase social exclusion in the domains outlined in this chapter. Decisive measures such as the advancement towards a person-centred model of care, the strengthening of social relationships both inside and outside the institution, or the consideration of these older residents as adult citizens whose opinions should be taken into account, are not guaranteed in post-pandemic times. And the risk of increased, rather than progressively reduced, social exclusion, is particularly at stake.

\section{References}

Adler, R., \& Goggin, J. (2005). What do we mean by "civic engagement"? Journal of Transformative Education, 3, 236-253. https://doi.org/10.1177/1541344605276792.

Allan, K., \& Killick, J. (2014). Communication and relationships: An inclusive social world. In M. Downs \& B. Bowers (Eds.), Excellence in dementia care (pp. 240-255). London: Open University Press.

Alzheimer's Disease International. (2013). World Alzheimer report 2013 'Journey of caring: An analysis of long-term care for dementia. London: Alzheimer's Disease International. https:// www.alz.co.uk/research/WorldAlzheimerReport2013.pdf.

Alzheimer's Society. (2007). Home from home. London: Alzheimer's Society.

Alzheimer's Society. (2016). Fix dementia care: NHS and care homes. London: Alzheimer's society. https://www.alzheimers.org.uk/sites/default/files/migrate/downloads/fix_dementia_care_ nhs_and_care_homes_report.pdf.

Andersen, J., \& Bilfeldt, A. (2016). Action research in nursing homes. Action Research, 14, 19-35. https://doi.org/10.1177/1476750315569082.

Anderson, K. A., \& Dabelko-Schoeny, H. I. (2010). Civic engagement for nursing home residents: A call for social work action. Journal of Gerontological Social Work, 53, 270-282. https://doi. org/10.1080/01634371003648323.

Appelbaum, P. S., Bonnie, R. J., \& Karlawish, J. H. (2005). The capacity to vote of persons with Alzheimer's disease. The American Journal of Psychiatry, 162, 2094-2100. https://doi. org/10.1176/appi.ajp.162.11.2094. 
Baldwin, C. (2008). Narrative(,) citizenship and dementia: The personal and the political. Journal of Aging Studies, 22, 222-228. https://doi.org/10.1016/j.jaging.2007.04.002.

Bartlett, R., \& Connor, D. O. (2010). Broadening the dementia debate towards social citizenship. Bristol: The Policy Press.

Bilfeldt, A., Mahler, M., \& Soegaard Joergensen, M. (2018). Pårørendesamarbejde og psykisk arbejdsmiljø. In A. Bilfeldt et al. (Eds.), Den ufardige fremtid. Aalbord: AAU.

Bonnie, R. J., Freedman, P., \& Guterbock, T. M. (2018). Voting by senior citizens in long-term care facilities. Election Law Journal: Rules, Politics, and Policy, 12, 293-304. https://doi. org/10.1089/elj.2012.0187.

Brooker, D. (2004). What is person-centred care in dementia? Reviews in Clinical Gerontology, 13, 215-222. https://doi.org/10.1017/S095925980400108X.

Brown, A., \& Draper, P. (2003). Accommodative speech and terms of endearment: Elements of a language mode often experienced by older adults. Journal of Advanced Nursing, 41, 15-21. https://doi.org/10.1046/j.1365-2648.2003.02500.x.

Cahill, S. (2018). Dementia and human rights. Bristol: Policy Press.

Cassie, K. M., \& Cassie, W. E. (2012). Organizational and individual conditions associated with depressive symptoms among nursing home residents over time. The Gerontologist, 52, 812-821. https://doi.org/10.1093/geront/gns059.

Choi, N. G., Ransom, S., \& Wyllie, R. J. (2008). Depression in older nursing home residents: The influence of nursing home environmental stressors, coping, and acceptance of group and individual therapy. Aging and Mental Health, 12, 536-547. https://doi. org/10.1080/13607860802343001.

Cipriani, J., Faig, S., Ayrer, K., Brown, L., \& Johnson, N.C. (2006). Altruistic activity patterns among long-term nursing home residents. Physical \& Occupational Therapy in Geriatrics, 24, 45-61. https://doi.org/10.1080/J148v24n03_04.

Doyle, P. J., \& Rubinstein, R. L. (2013). Person-centered dementia care and the cultural matrix of othering. The Gerontologist, 54, 952-964. https://doi.org/10.1093/geront/gnt081.

Drageset, J. (2004). The importance of activities of daily living and social contact for loneliness: A survey among residents in nursing homes. Scandinavian Journal of Caring Sciences, 18, 65-71. https://doi.org/10.1111/j.0283-9318.2003.00251.x.

Drageset, J., Kirkevold, M., \& Espehaug, B. (2011). Loneliness and social support among nursing home residents without cognitive impairment: A questionnaire survey. International Journal of Nursing Studies, 48, 611-619. https://doi.org/10.1016/j.ijnurstu.2010.09.008.

Edvardsson, D., Fetherstonhaugh, D., \& Nay, R. (2010). Promoting a continuation of self and normality: Person-centred care as described by people with dementia, their family members and aged care staff. Journal of Clinical Nursing, 19, 2611-2618. https://doi. org/10.1111/j.1365-2702.2009.03143.x.

Fine, M. (2015). Cultures of care. In J. Twigg \& W. Martin (Eds.), Routledge handbook of cultural gerontology (pp. 269-276). Abingdon: Routledge.

Goffman, E. (1961). Asylums: Essays on the social situation of mental patients and other inmates. Garden City: Anchor Books.

Hanratty, B., Stow, D., Collingridge Moore, D., Valtorta, N. K., \& Matthews, F. (2018). Loneliness as a risk factor for care home admission in the English longitudinal study of ageing. Age and Ageing, 47, 896-900. https://doi.org/10.1093/ageing/afy095.

Hjort, K. (2009). Competence and development in the public sector: Development or dismantling of professionalism? In K. Illeris (Ed.), International perspectives on competence development. Developing skills and capabilities (pp. 112-123). LondonlNew York: Routledge.

Karlawish, J., Bonnie, R., Appelbaum, P., Kane, R., Lyketsos, C., Karlan, P., et al. (2008). Identifying the barriers and challenges to voting by residents in nursing homes and assisted living settings. Journal of Aging and Social Policy, 20, 65-79. https://doi.org/10.1300/J031v20n01_04.

Klinedinst, N. J., \& Resnick, B. (2014). Volunteering and depressive symptoms among residents in a continuing care retirement community. Journal of Gerontological Social Work, 57, 52-71. https://doi.org/10.1080/01634372.2013.867294. 
Leedahl, S. N., Sellon, A. M., \& Gallopyn, N. (2017). Factors predicting civic engagement among older adult nursing home residents. Activities, Adaptation \& Aging, 41, 197-219. https://doi. org/10.1080/01924788.2017.1310581.

Löfqvist, C., Granbom, M., Himmelsbach, I., Iwarsson, S., Oswald, F., \& Haak, M. (2013). Voices on relocation and aging in place in very old age-A complex and ambivalent matter. The Gerontologist, 53(6), 919-927. https://doi.org/10.1093/geront/gnt034.

Marshall, T. H. (1950). Citizenship and social class, and other essays. Cambridge: Cambridge University Press.

Moffatt, S., \& Glasgow, N. (2009). How useful is the concept of social exclusion when applied to rural older people in the United Kingdom and the United States? Regional Studies, 43(10), 1291-1303. https://doi.org/10.1080/00343400903002697.

Nyqvist, F., Cattan, M., Andersson, L., Forsman, A. K., \& Gustafson, Y. (2013). Social capital and loneliness among the very old living at home and in institutional settings: A comparative study. Journal of Aging and Health, 25, 1013-1035. https://doi.org/10.1177/0898264313497508.

O'Dwyer, C. (2013). Official conceptualizations of person-centered care: Which person counts? Journal of Aging Studies, 27, 233-242. https://doi.org/10.1016/j.jaging.2013.03.003.

O'Dwyer, C., \& Timonen, V. (2010). Rethinking the value of residents 'councils: Observations and lessons from an exploratory study. Journal of Applied Gerontology, 29, 762-771. https:// doi.org/10.1177/0733464809348002.

Paque, K., Bastiaens, H., Van Bogaert, P., \& Dilles, T. (2018). Living in a nursing home: A phenomenological study exploring residents' loneliness and other feelings. Scandinavian Journal of Caring Sciences, 32, 1477-1484. https://doi.org/10.1111/scs.12599.

Petriwskyj, A., Gibson, A., \& Webby, G. (2018). What does client "engagement" mean in aged care? An analysis of practice. Ageing and Society, 38, 1350-1376. https://doi.org/10.1017/ S0144686X17000095.

Phelan, A. (2015). Protecting care home residents from mistreatment and abuse: On the need for policy. Risk Management and Healthcare Policy, 8, 215-223. https://doi.org/10.2147/ RMHP.S70191.

Pitkala, K. H. (2016). Loneliness in nursing homes. Journal of the American Medical Directors Association, 17, 680-681. https://doi.org/10.1016/j.jamda.2016.04.007.

Resnick, B., Klinedinst, J., Dorsey, S., Holtzman, L., \& Abuelhiga, L. S. (2013). Volunteer behaviour and factors that influence volunteering among residents in continuing care retirement communities. Journal of Housing for the Elderly, 27, 161-176. https://doi.org/10.1080/0276389 3.2012.754820.

Roberts, T., \& Bowers, B. (2015). How nursing home residents develop relationships with peers and staff: A grounded theory study. International Journal of Nursing Studies, 52, 57-67. https://doi.org/10.1016/j.ijnurstu.2014.07.008.

Sabat, S. R. (2006). Mind, meaning, and personhood in dementia: The effects of positioning. In J. C. Hughes, S. J. Louw, \& S. R. Sabat (Eds.), Dementia: Mind, meaning, and the person (pp. 287-302). Oxford: Oxford University Press.

Scholl, J. M., \& Sabat, S. R. (2008). Stereotypes, stereotype threat and ageing: Implications for the understanding and treatment of people with Alzheimer's disease. Ageing and Society, 28, 103-130. https://doi.org/10.1017/S0144686X07006241.

Selbæk, G., Kirkevold, Ø., \& Engedal, K. (2007). The prevalence of psychiatric symptoms and behavioural disturbances and the use of psychotropic drugs in Norwegian nursing homes. International Journal of Geriatric Psychiatry, 22, 843-849. https://doi.org/10.1002/gps.1749.

Serrat, R., Scharf, T., Villar, F., \& Gómez, C. (2020). Fifty-five years of research into older people's civic participation: Recent trends, future directions. The Gerontologist, 60(1), e38-e51.

Stone, R. I., \& Bryant, N. (2012). The impact of health care reform on the workforce caring for older adults. Journal of Aging \& Social Policy, 24, 188-205. https://doi.org/10.1080/0895942 0.2012 .659144 . 
Szebehely, M. (2005). Care as employment and welfare provision. Child care and elder care in Sweden at the dawn of the 21 st century. In H. M. Dahl \& T. R. Eriksen (Eds.), Dilemmas of care in the Nordic welfare state. Continuity and change. Aldershot: Ashgate.

Szebehely, M., Stranz, A., \& Strandell, R. (2017). Vem ska arbeta i framtidens äldreomsorg? Stockholm: Department of Social Work, Stockholm Universitet.

Van Malderen, L., Mets, T., De Vriendt, P., \& Gorus, E. (2013). The active ageing-concept translated to the residential long-term care. Quality of Life Research, 22, 929-937. https://doi. org/10.1007/s11136-012-0216-5.

Ward, R., Vass, A. A., Aggarwal, N., Garfield, C., \& Cybyk, B. (2008). A different story: Exploring patterns of communication in residential dementia care. Ageing \& Society, 28(5), 629-651.

Westerhof, G. J., van Vuuren, M., Brummans, B. H., \& Custers, A. F. (2013). A Buberian approach to the co-construction of relationships between professional caregivers and residents in nursing homes. The Gerontologist, 54, 354-362. https://doi.org/10.1093/geront/gnt064.

Wiersma, E., \& Dupuis, S. L. (2010). Becoming institutional bodies: Socialization into a long-term care home. Journal of Aging Studies, 24, 278-291. https://doi.org/10.1016/j.jaging.2010.08.003.

Williams, K. N., Ilten, T. B., \& Bower, H. (2016). Meeting communication needs: Topics of talk in the nursing home. Journal of Psychosocial Nursing and Mental Health Services, 43, 38-45. https://doi.org/10.3928/02793695-20050701-05.

Williams, K. N., Perkhounkova, Y., Herman, R., \& Bossen, A. (2017). A communication intervention to reduce resistiveness in dementia care: A cluster randomized controlled trial. The Gerontologist, 57, 707-718. https://doi.org/10.1093/geront/gnw047.

Yuen, H. K. (2002). Impact of an altruistic activity on life satisfaction in institutionalized elders: A pilot study. Physical and Occupational Therapy in Geriatrics, 20, 125-135. https://doi. org/10.1080/J148v20n03_08.

Open Access This chapter is licensed under the terms of the Creative Commons Attribution 4.0 International License (http://creativecommons.org/licenses/by/4.0/), which permits use, sharing, adaptation, distribution and reproduction in any medium or format, as long as you give appropriate credit to the original author(s) and the source, provide a link to the Creative Commons license and indicate if changes were made.

The images or other third party material in this chapter are included in the chapter's Creative Commons license, unless indicated otherwise in a credit line to the material. If material is not included in the chapter's Creative Commons license and your intended use is not permitted by statutory regulation or exceeds the permitted use, you will need to obtain permission directly from the copyright holder. 